\title{
DA LAMA AO CAOS E DO CAOS AO CÉREBRO: UMA APROXIMAÇÃO DELEUZIANA A CHICO SCIENCE E NAÇÃO ZUMBI
}

\section{Jair Tadeu da Fonseca*}

Resumo: Ensaio sobre alguns conceitos de Gilles Deleuze (e Felix Guattari) acerca de arte e pensamento, considerando principalmente aspectos da obra de Chico Science e Nação Zumbi. As reflexões suscitadas por essa obra permitem considerar de outra forma, e mesmo questionar, o que seria "regional" em nosso tempo e considerar também um novo devir da consciência - um devir minoritário.

Palavras-chave: Gilles Deleuze. Chico Science e Nação Zumbi. Arte. Pensamento. Região. Devir.

Eu vim com a Nação Zumbi / ao seu ouvido falar / quero ver a poeira subir / e muita fumaça no ar/ cheguei com meu universo / e aterrizo no seu pensamento / trago as luzes dos postes nos olhos / rios e pontes no coração / Pernambuco embaixo dos pés / minha mente na imensidão.

Chico Science e Nação Zumbi

Ver os filmes de Glauber Rocha ou ouvir as canções de Chico Science são experiências que permitem um trabalho cartográfico dos mais interessantes no campo dos estudos da cultura brasileira. Principalmente, porque as respectivas obras, elas próprias, são já modos de criar e registrar as andanças, escavações, rastejamentos e sobrevôos da consciência por territórios nunca dantes percorridos,

- Pesquisador e professor de Literatura Brasileira e Teoria da Literatura na Universidade Federal de Ouro Preto, Mestre em Teoria da Literatura e Doutor em Literatura Comparada pela Universidade Federal de Minas Gerais, em que desenvolveu estudos sobre a obra de Glauber Rocha. Sobre esse tema, publicou diversos trabalhos. É cancionista, com cinco discos gravados. 
pelo menos do modo como esses nossos argonautas das imagens e dos sons o fizeram.

O que é interessante é precisamente o fato de as obras de Glauber e Chico Science, em momentos e áreas artísticas diferentes, retomarem as pisadas trilhas do chamado regionalismo, outrora tão presente, e mesmo preponderante, no campo das artes no Brasil, principalmente na literatura, notadamente em termos do Nordeste. Não por acaso, justamente do Nordeste partem Glauber e Chico. E partir significa aqui muito mais do que simplesmente criar a partir de uma dada região geográfica, mas também deslocar-se, migrar, abandonar a terra e carregá-la consigo enquanto signos - imagens, sons, palavras, cores, ritmos - que se correspondem ou não com outros signos de outros campos, mas que de todo modo proliferam, atuam, interferem. Não é à toa que os dois artistas "regionalistas" de que falamos sejam justamente duas poderosas expressões "nacionais" no cenário internacional - em suma, eles não são regionalistas, mas partem de uma região, de um lugar menor, e então a encontram. Sua arte é menor, não engrossa o coro da maioria, vale dizer, do uno, do todo, do poder central, mas colabora na criação de outras potências polifônicas e epifânicas.

Partir significa criar linhas de fuga no melhor (e menor) dos todos possíveis: o todo que é o aberto. Partir é encontrar e perder o norte, pelo desnorteamento de todos os sentidos. O que significam o regional, o nacional, o internacional ou o transnacional, o universal, se recusamos os limites territoriais e políticos com relação à arte, embora tenhamos que reconhecê-los? Além disso, em nossas considerações sobre arte e pensamento, como considerar suas fronteiras? Ainda mais, nos territórios da arte, como perceber as passagens e barreiras entre os diferentes espaços constituídos pelas modalidades artísticas? A "geofilosofia" de Gilles Deleuze pode nos ajudar a tentar responder essas questões e mesmo a questioná-las, por sua vez.

É importante ressaltar que Glauber e Chico Science não foram escritores, mas escreveram. Seriam, de algum modo, escritores menores? O fato é que do vácuo deixado pela potente literatura regionalista nordestina (modernista e popular), no cenário nacional, surgem artistas dedicados ao cinema e à música, cujas obras, entretanto, ligam-se estreitamente à ficção e à poesia dos escritores e poetas de sua terra e de seu povo. 
E aqui entram dois termos tão perigosos - povo e terra - que até podem chocar certos leitores desavisados que se debruçam sobre a obra de Deleuze e se deparam com o despudor com que o filósofo faz uso dessas palavras cansadas, mas tornadas tão frescas. Podem ficar chocados principalmente os que, lendo superficialmente a pele do "corpo sem órgãos" de seus textos, não são capazes de compreendêlos em profundidade, a qual não é necessariamente vertical. Há a vertigem das dobras, as cavidades surpreendentes, as ondulações e as asperezas e o muito liso dos textos em que estão os conceitos. O deslizar sobre a superfície infinita dos sentidos - em mais de um sentido - é que produz o abismar-se nas (im)possibilidades do pensamento, como no surf ou no skate, que da pele das ruas e oceanos nos oferecem as profundezas abissais e os subterrâneos das cidades, como suas potências regionais marinhas e urbanas nos oferecem o que se pode conhecer e principalmente o insondável.

O pensamento filosófico acaba sempre por chegar ao impensável, aliás o pensar acaba (ou principia) por ser um poço sem fundo, que bem pode ser uma superfície infinita. $O$ que as leituras superficiais, no mau sentido, de Deleuze não percebem são os volteios, as vertigens, os acidentes do terreno filosófico em que se pensam os planos de imanência e as janelas que se recortam para o caos. Não se trata de matar os conceitos, transformando-os em clichês, de utilizar conceitos como quem pega um táxi, seguro e confortável, que alguém dirige por nós e que nos conduz a um destino seguro. Trata-se de pensar os conceitos, imaginá-los e criá-los por nossa conta e risco, como num esporte radical, como na arte.

O exercício do pensamento permite sim utilizar palavras "malditas", como povo, terra, maioria e minoria, por exemplo, apesar de elas terem se tornado clichês, ou justamente por isso é que elas devem ser incorporadas ao exercício de pensar que as distende e revira, estende, enxuga e revigora - torna-as algo menor. Se elas não podem ser desautomatizadas, se não podemos deslizar e errar com elas, deslocá-las, se elas não se movem, é porque estão mortas. Não é esse o caso.

Com relação ao problema do regional, o que nos interessa é perceber não o óbvio da arte num lugar, mas uns lugares na arte. Compreende-se aqui a obra de Glauber e de Chico Science como contrapontos ruidosos às concepções estreitas de regionalismo (e 
ainda de nacionalismo) e seus usos oficiais e pára-oficiais institucionais - e nos propomos a pensar, a partir do que seria "regional" no trabalho deles, alguns elementos para um novo devir da consciência - um devir minoritário, de que trata Deleuze, em algumas de suas obras.

Para o filósofo, o povo não é uma entidade a serviço da mistificação política, nem um simples plural de pessoa, mas um devir, uma potência coletiva, um modo de denominar uma força social que não é a dos dominadores, nem a dos lugares-comuns. Deleuze "recupera" a palavra povo, quando a redime do reino dos clichês, e a torna, junto ao conceito de devir, algo que desmente o sentido de povo como entidade amorfa e sujeita à manipulação populista, entre outros usos. O povo não é maioria simplesmente, é uma composição molecular diferenciada e diferenciadora, vista de um ponto de vista qualitativo e não quantitativo. Só é possível pensar o povo através das minorias porque o maior se define pela ampliação conservativa do poder, pela constância do que é unívoco, e o menor, pela potência do que é variável, múltiplo, heterogêneo. Maioria e minoria não se definem simplesmente pela quantidade, mas pela qualidade diferencial dada pelas situações de poder: "A maioria não designa uma quantidade maior, mas aquele padrão em relação ao qual as outras quantidades, quaisquer que elas sejam, serão ditas menores" (DELEUZE, BENE, 1979, p. 124). O devir é um modo de comprender o que é menor e maior para o filósofo, segundo o qual todo devir é minoritário, nunca majoritário (Cf. DELEUZE, GUATTARI, 1984).

Tais concepções permitem que se compreendam tanto o fato de Deleuze e Guattari considerarem menor a literatura de um autor "consagrado" como Kafka, quanto suas posturas sobre a revolução: de fato, não interessa à revolução política è è escrita de Kafka, enquanto devires, sua fixação institucional. Não importam o stalinismo que destruiu a revolução soviética, mumificando-a como o cadáver de Lênin, e o kafkiano lugar-comum a que a obra do escritor é remetida tantas vezes, se considerarmos a literatura e a revolução não como resultados de um processo, mas como o escapar sem fím da duração, como manifestação do intempestivo e resistência ao institucional, à normalização e à normatização. Ao tempo, contrapõe-se o intempestivo e o inconformismo toma forma. 
É necessário ter cuidado com as armadilhas das armadilhas que se chamam de história e inconsciente: a despeito de si mesmos, um autor e sua obra - ou um povo oprimido e pobre, ou um grupo que se autodefine racial ou sexualmente como negro ou gay - podem ser neutralizados institucionalmente e se tornarem "maiores". A burocracia da ditadura stalinista, a canonização acadêmica de Kafka ou a institucionalização das questões sexuais e raciais parecem endereçar aos camponeses e operários, à obra do escritor e às feministas, aos gays e negros um mesmo recado: "não nos causem mais problemas, juntem-se a nós, no grande gueto da maioria!"

Isso não é fruto de uma visão maniqueísta ou paranóica das coisas, mas um diagnóstico do grave estado das coisas em nossos tempos e espaços ditos pós-modernos, em que a capitulação parece ser a chave que abre as portas das "sociedades de controle" (DELEUZE, 1992, p. 219-226) e as fecha. Sejamos leves e escapemos, para agir, se temos o diagnóstico.

Então, operação por operação, cirurgia por cirurgia, pode-se conceber o contrário: como "minorar", termo empregado pelos matemáticos, como impor um tratamento menor ou de minoração para extrair os devires contra a história, as vidas contra a cultura, os pensamentos contra a doutrina, as graças ou desgraças contra o dogma (DELEUZE, BENE, 1979, p. 9).

Glauber Rocha e Chico Science, sendo pensadores/artistas do cinema e do som, não teriam mais raízes (termo muito utilizado como imagem-clichê da cultura, até recentemente) no solo nordestino e brasileiro, mas rizomas, que fazem parte da múltipla horizontalidade pela subtração, não pela adição, sendo a região Nordeste uma parte (menor, mas não no sentido geográfico, obviamente) do Brasil: mangue em Chico Science, sertão em Glauber Rocha; em ambos, cidades. Não se trata mais da árvore da literatura e da cultura brasileiras, com suas raízes na Europa, tronco que se eleva e galhos que se curvam até o Brasil, na imagem tão recorrente e da qual parte, por exemplo, o importante estudo de Antonio Candido sobre a Formação da literatura brasileira.

A perspectiva rizomática, proposta e posta em prática por Deleuze e Guattari, tem mais a ver com nossos tempos e espaços de 
infovias, redes sofisticadas de comunicação e informação, em meio a um ambiente social, política e ecologicamente degradado, do que $a$ árvore grande, sólida, una e vertical: delimitada, limitada e limitadora. Muito já falamos de raízes e galhos, agora falamos de rizomas que se espraiam nos platôs, "uma contínua região de intensidades, vibrante em si mesma, que é desenvolvida evitando orientar-se em direção a um ponto culminante ou em direção a um fim exterior" (DELEUZE, GUATTARI, 1984, p. 32).

Considerando o papel da geografia na literatura americana, Deleuze e Guattari afirmam a cartografia como necessidade do sistema rizomático, já que o mapeamento permite medir as relações entre a "máquina" literária e as outras máquinas. No caso de Glauber e Chico Science, é possível fazer uma "rizoanálise" de suas máquinas cinematográfica e musical, tendo em vista as relações que elas têm, por vias sobre/subterrâneas, com as máquinas literárias, sociais, culturais e políticas do que um dia se chamou regionalismo.

As "máquinas artísticas" (livros, discos, filmes) funcionam coordenadamente, embora não haja um plano prévio de organização, de modo a recortar e abrir janelas no caos. Há coordenadas também entre a máquina conceitual e a máquina artística. Como o filósofo e o cientista trazem do caos, respectivamente, as variações e as variáveis, "o artista traz do caos variedades que não constituem mais uma reprodução do sensível no órgão, mas erigem um ser do sensível, um ser da sensação, sobre um plano de composição, anorgânico, capaz de restituir o infinito" (DELEUZE, GUATTARI, 1992, p. 260). Se temos planos de composição na arte, habitados por figuras estéticas, na filosofia temos planos de imanência em que atuam personagens conceituais. Com destino certo ou ainda vagabundos, os personagens conceituais perambulam e se fixam em seus planos como potências de conceptos e as figuras estéticas como potências de afectos e perceptos: "A arte e a filosofia recortam o caos e o enfrentam, mas não é o mesmo plano de corte, não é a mesma maneira de povoá-lo; aqui, constelação de universo ou afectos e perceptos, lá, complexos de imanência e conceitos. A arte não pensa menos que a filosofia, mas pensa por afectos e perceptos" (DELEUZE, GUATTARI, 1992, p. 88).

Dos personagens conceituais de Deleuze, escolhemos uma das três "filhas do Caos", uma das caóides, "realidades produzidas em 
planos que recortam o caos" (DELEUZE, GUATTARI, 1992, p. 267), que seria a arte. Essa caóide é capaz de nos ajudar a compreender algumas das figuras estéticas de Glauber e de Chico Science, que pensam e nos fazem repensar as relações entre o regional, o nacional, o internacional, o universal, o cósmico. Não necessariamente nessa ordem. Pretensão? Sobrevalorização da obra desses artistas? Não, pois, como escreve Deleuze, "a sensação não é menos cérebro que o conceito", sendo que "o cérebro é o espírito mesmo" (DELEUZE, GUATTARI, 1992, p. 270-271).

Vejamos como é possível experimentar as mutações do que pode parecer regional, mas é devir-minoritário e devir universal, e "um devir-minoritário universal" (DELEUZE, BENE, 1979, p. 129), como escreve Deleuze, a respeito do dramaturgo, cineasta e ator Carmelo Bene, que se recusa a fazer "teatro regionalista" e afirma: "Faço teatro popular. Étnico. Mas é o povo que falta" (BENE citado por DELEUZE, 1990, p. 259).

Bene fornece a Deleuze a pista para pensar o cinema politico, principalmente o do chamado Terceiro Mundo, particularmente o de Glauber Rocha, de cuja obra se ocupa em um dos capítulos de $A$ imagem-tempo, mas também nos oferece um meio de pensar manifestações importantes em outros setores da produção artística brasileira, como a música popular, notadamente o Mangue Beat (ou Bit), particularmente as canções e sons de Chico Science e Nação Zumbi. Algo raro nos meios musicais da juventude, atualmente, Chico Science surge como um articulador e agitador cultural, alguém preocupado com políticas culturais e outras políticas, sem que isso se sobreponha ao seu trabalho propriamente artístico. Assim como Glauber.

Assistir a um show de Chico Science e a um filme de Glauber seriam modos de perceber outros lugares e eventos do que se costuma chamar de regionalismo, folclore, cultura popular - tudo o que poderia ser devir, ser menor, e infinitamente potente e vasto, em sua região rizomática, e que acaba incorporado ao maior, à historia, até acabar, morrer e ser mumificado como folclore, moda literária superada, conceito político tornado inútil. Porque o povo falta é que Glauber e Chico Science criam linhas de fuga da região, do folclore e da cultura popular e, justamente porque ele falta, é que se reiventa, reconectado aos rizomas sobre/subterrâneos, telúricos, elétricos, eletrônicos, 
fotográficos, digitais, informacionais e políticos da arte e do pensamento desses artistas. Um povo em devir existe e resiste em filmes, textos, sons, canções.

A Nação Zumbi é um devir-minoritário do povo brasileiro e os "caranguejos com cérebro" são o seu devir-animal. No encarte do primeiro disco de Chico Science e Nação Zumbi temos o "manifesto" Caranguejos com cérebro, em que se trabalha o conceito de mangue ( "cena"). Seria esse nosso último manifesto modernista, ou neotropicalista, ou nosso primeiro manifesto pós-modernista? Isso não importa, pois Caranguejos com cérebro não se filia a nada (não seremos nós que o filiaremos), nem pretende capitanear coisa alguma, embora seja um importante registro do "movimento" Mangue Beat, que nem se constitui exatamente como um movimento, no sentido usual do Modernismo, mas busca pensar estética e politicamente o coletivo, de um modo pouco comum às manifestações artísticas pósmodernas. Por que se preocupar com o pensar as conexões entre a região e o resto e escrever a respeito? Diz o "manifesto": "O objetivo é engendrar um 'circuito energetico', capaz de conectar as boas vibrações dos mangues com a rede mundial de circulação de conceitos pop".

A antena parabólica nutrida pela lama da terra dos - manguezais, a mesma lama de que é feito o corpo', ou em que ele se desfaz, é conectada ao mundo e pode ser entendida como uma figura estética análoga de certo modo à figura filosófica do rizoma. Aos jovens artistas do Recife não interessa manter a velha postura regionalista tradicional do Pernambuco, pois há outras conexões: "Os mangueboys e manguegirls são indivíduos interessados em quadrinhos, TV interativa, antipsiquiatria, Bezerra da Silva, hip hop, midiotias, artismo, música de rua, John Coltrane, acaso, sexo não virtual, conflitos étnicos e todos os avanços da química aplicada no terreno da alteração e expansão da consciência".

1 Cf. Corpo de lama, antonionesca canção do segundo disco de Chico Science e Nação Zumbi, Afrociberdelia: "Este corpo de lama que tu vês/é apenas a imagem do que soul". 
Se o "movimento" Mangue Beat surge como contraponto ruidoso à harmonia do Movimento Armorial, nao lhe interessa também a negação dessa e de outras manifestações artísticas e musicais do Pernambuco. Na verdade, tudo o que é interessante lhe interessa: do Armorial do velho Ariano Suassuna à Ciranda do Velho Faceta. Principalmente, não interessa aos "mangueboys e manguegirls" o confinamento regional/nacionalista, mas a formação de nações realmente imaginadas, tão menores que podem assumir a forma que se queira. Daí as conexões Brasil-África-Europa-Estados Unidos, pela via das nações do maracatu pernambucano e da Zulu Nation do hip hop de Afrika Bambaataa, passando pela no man's land do rock. No palco, ao som dos tambores e das guitarras elétricas, ocorre a metamorfose não se sabe do quê, mas certamente de potências: Chico vai de cantor de rock-rap a guerreiro dançarino afroíndio, num maracatu tecnológico, mas molecular, atômico.

Ainda no encarte do primeiro disco, pequenos textos ilustrados trazem suas figuras estéticas para povoar os planos de composição de Da lama ao caos: meio humano, meio caranguejo, temos o devir-animal do povo na metamorfose social-geográfica, reevolucionária - zoo-regional -, um devir-minoritário. Segundo esses textos, a nova espécie Chamagnathus granulatus sapiens resulta de uma mutação ocasionada pelo consumo de cerveja feita com água contaminada pela baba de caranguejo dos manguezais e pelos efeitos da "afrociberdelia", que alterou o comportamento da população, a qual passou a "movimentar-se de maneira tal, que findou por condensar e dimensionar esses ingredientes". Há no encarte, por exemplo, um texto no verso de um postal:

Muita coisa está mudando. Depois do deslocamento dos bairros, agora enfrentamos esses mutantes. De longe, a cidade parece normal, mas chegando perto... Aqui em casa papai foi o único que sucumbiu ao mal. A família está em polvorosa. Não levamos ele para o casamento de Joanatária, mas já o aceitamos na mesa.

Os Chamagnatus granulatus sapiens ocupam a cidade e, "sintonizados nas frequências moduladas, colocam em risco as superestruturas da ordem estabelecida". Para Deleuze, o devir-animal relaciona-se justamente com a emissão de partículas e se dá em função 
de relações de movimento e fixação, através de zonas de proximidade, indeterminação e incerteza. Fora do campo que se conhece e se pode controlar, cria-se o "corpo sem órgãos", capaz de produzir o deviranimal, o animal molecular de nós mesmos, uma de nossas linhas de fuga. As micropolíticas, a redistribuição dos desejos são justamente as mudanças moleculares, as mudanças qualitativas e não as quantitativas, como as dos objetos molares. Entre os objetos moleculares do Homo sapiens e do Chamagnathus granulatus, há evidentemente diferenças de natureza, mas há uma troca de partículas capaz de criar mutantes sem órgãos, séries sem órgãos ou com órgãos forjados, provisórios, indeterminados - formas disjuntivas: corpos sem órgãos. De fato, não é o homem que se torna animal, mas é o tornar-se animal que produz o homem e evidencia seu potencial de transformação, seu inacabamento, seu devir.

Seria interessante pensar a questão do que foi ou é regional, na perspectiva do devir-minoritário de que fala Deleuze, nos filmes e textos de Glauber, nos anos 1960, e nas músicas e textos de Chico Science, na década de 1990. A arte que parte de uma região específica é confinada, pelos centros de decisão, no gueto regionalista que designa o exótico como um modo excludente de tratar o outro, o diferente, o menor e circunscrevê-los. Cabe perguntar por que a literatura e a música do Rio ou de São Paulo não são regionais, ou por que a música norte-americana ou a inglesa não são catalogadas como world music.

As obras de Glauber e de Chico Science são respostas a essas falácias, e Deleuze, como se vê, oferece ferramentas e máquinas filosóficas capazes de se conectarem com as máquinas artísticas de que tratamos. Assim, podemos contribuir para alastrar esses rizomas pela subtração que potencializa, combatendo as parafernálias críticas parasitárias que apenas se acrescentam, como excrescências, aos seus "objetos", e os matam ou neutralizam. Espera-se que este trabalho não sirva para um fim tão deletério.

Nessa perspectiva, como fizeram Deleuze, Guattari, Glauber, Chico Science e tantos outros, é necessário escapar pelos rizomas, cruzando as raízes que se fixaram, e se espraiar por outras praias, terras do sol e manguezais, até que, por alguma nesga de solo, se alcance o caosmos e se perca a conta da idade da terra. O percurso: da lama ao caos e do caos ao cérebro. 
UMA APROXIMAÇĀO DELEUZIANA A CHICO SCIENCE E NAÇÃO ZUMBI

Referências

DELEUZE, Gilles. A imagem-tempo. Trad. Eloísa Ribeiro. São Paulo: Brasiliense, 1990.

DELEUZE, Gilles. Conversações. Trad. Peter Pal Pelbart. Rio de Janeiro: Ed. 34, 1992.

DELEUZE, Gilles; BENE, Carmelo. Superpositions. Paris: Minuit, 1979.

DELEUZE, Gilles; GUATTARI, Felix. A thousand plateaus: capitalism and schizophrenia. Trans. Brian Massumi. Minneapolis: University of Minnesota Press, 1984.

DELEUZE, Gilles. Kafka: por uma literatura menor. Trad. Júlio Castañon Guimarães. Rio de Janeiro: Imago, 1977.

DELEUZE, Gilles. O que é a filosofia? Trad. Bento Prado Jr. e Alberto Alonso Muñoz. Rio de Janeiro: Ed. 34, 1992.

Discografia

CHICO SCIENCE E NAÇÃO ZUMBI. Afrociberdelia. Rio de Janeiro: Sony, 1996.

CHICO SCIENCE E NAÇÃO ZUMBI Da lama ao caos. Rio de Janeiro: Sony, 1995. 